\title{
NOTA
}

\section{DETERMINAÇÃO DE FÓSFORO MICROBIANO: COMPARAÇÃO ENTRE MÉTODOS E COBERTURAS FLORESTAIS $^{(1)}$}

\author{
Ecila Mercês de Albuquerque Villani ${ }^{(2)}$, Nairam Félix de $\operatorname{Barros}^{(3)}$, \\ Roberto Ferreira Novais ${ }^{(3)}$, Eduardo de Sá Mendonça ${ }^{(3)}$ \& Guilherme \\ Julião Zocolo ${ }^{(4)}$
}

\section{RESUMO}

Muitos trabalhos mostram a importância da biomassa microbiana do solo (BMS), principalmente como fonte/dreno de $\mathrm{C}$ e de $\mathrm{N}$ em plantações florestais; contudo, são escassos os trabalhos relacionados ao fósforo microbiano (PBM), sobretudo aqueles relativos aos métodos de determinação do PBM nesses ecossistemas. $O$ presente trabalho foi realizado com o objetivo de avaliar métodos de determinação do PBM em solo com diferentes coberturas vegetais. $O$ trabalho consistiu da análise de amostras de Latossolo Vermelho-Amarelo distrófico muito argiloso (LVAd) localizado no município de Viçosa (MG), coletadas nas profundidades de 0 a 5 e 5 a $10 \mathrm{~cm}$, em áreas com as seguintes coberturas vegetais: pínus (Pinus taeda), eucalipto (Eucalyptus grandis) e floresta nativa. Para determinação do $\mathbf{P}$ microbiano, foram empregados os métodos fumigação-extração (FE), irradiação com micro-ondas-extração (IE) e irradiação com micro-ondasextração com membrana de troca aniônica (EMTA). Em termos gerais, menores teores de PBM foram obtidos com o método irradiação-extração. Considerando a cobertura vegetal, foi detectada diferença significativa entre os três métodos sob floresta de eucalipto e floresta nativa, principalmente na camada superficial. Sob pínus, apenas o método IE diferiu dos demais, na camada subsuperficial. Menores coeficientes de variação (CV) foram obtidos com o $\mathrm{FE}$, retratando maior precisão do método. Entretanto, o método IE mostrou-se, em termos operacionais, o mais adequado à determinação do PBM quando se tem maior número de amostras.

\footnotetext{
${ }^{(1)}$ Parte da Tese de Doutorado do primeiro autor apresentada ao Departamento de Solos, Universidade Federal de Viçosa - UFV. Recebido para publicação em outubro de 2008 e aprovado em maio de 2009.

(2) Engenheira-Agrônoma, DS em Solos e Nutrição de Plantas, UFV. Rua Cesário Alvin 483/01, CEP $36062-280$ Juiz de Fora (MG). E-mail: ecilavillani@yahoo.com.br

(3) Professor do Departamento de Solos, Universidade Federal de Viçosa - UFV. Av. PH Rolfs s/n, CEP 36570-000 Viçosa (MG). Emails: nfbarros@ufv.br,rfnovais@ufv.br, esm@ufv.br

(4) Doutorando em Química, UNESP-Araraquara. E-mail: gjzocolo@yahoo.com.br
} 
Com relação às coberturas vegetais, a grande variabilidade observada nos CVs obtidos para cada cobertura, nos três métodos testados, inviabiliza a escolha de um único método que apresente maior precisão na avaliação do PBM.

Termos de indexação: fósforo microbiano, precisão, solos ácidos.

\title{
SUMMARY: EVALUATION OF MICROBIAL PHOSPHORUS: COMPARISON OF DETERMINATION METHODS IN FOREST SOILS
}

\begin{abstract}
Many studies have shown the importance of the soil microbial biomass, mainly as source/ sink of carbon (C) and nitrogen $(N)$ in forest stands. However, there are few studies focused on microbial $P(M P H)$, especially in relation to the determination methods of MPH in these ecosystems. For an evaluation of the methods used to determine microbial $P(M P H)$ in soils, three methods were evaluated: fumigation-extraction (FE); radiation with microwave-extraction (RE); and radiation by microwave-extraction with a membrane for anionic exchange (EMAE). Samples of a very clayey dystrophic Red-Yellow Latosol (LVAd) were collected at depths of $0-5 \mathrm{~cm}$ and 5-10 cm in soils under pine (Pinus taeda), eucalypt plantations (Eucalyptus grandis), and native forest, in Viçosa, state of Minas Gerais. In general, lower MPH contents were obtained by the RE than by the FE method. The MPH contents established by the three methods in the areas with eucalypt and native forest varied significantly in the surface layer. Under pine, only the RE method was significantly different in the 5-10 cm layer. The lowest coefficients of variation (CV) were obtained by FE, expressing the greater precision of this method. Under the studied conditions, however, where a large-scale analysis of samples is required, the RE method turned out to be, in terms of functionality, most adequate for the MPH determination. In relation to the stands, none of the three tested methods could be indicated as uniquely most precise method for the evaluation of the MPH, due to the great variability in the $C V$ for each forest type.
\end{abstract}

Index terms: microbial phosphorus, precision, acid soils.

\section{INTRODUÇÃO}

A biomassa microbiana é um componente da matéria orgânica do solo (MOS) muito importante no processo de decomposição desse material e na ciclagem de nutrientes (Moreira \& Siqueira, 2002). Muitos trabalhos mostram a importância dessa microbiota, principalmente como fonte/dreno de $\mathrm{C}$ e de $\mathrm{N}$ nos solos (Vargas \& Scholles, 2000; Oliveira et al., 2001; GamaRodrigues et al., 2005). Entretanto, são escassos na literatura os trabalhos relacionados ao fósforo microbiano (PBM) (He et al., 1997; Barroti \& Nahas, 2000; Schneider et al., 2001). As formas inorgânicas (Pi) e orgânicas $(\mathrm{Po})$ têm sido determinadas por métodos de fracionamento (Hedley et al., 1982; Cross \& Schlesinger, 1995), ou identificação da sua estrutura, por cromatografia ou ressonância magnética nuclear (Condron et al., 1985; Gil-Sotres et al., 1990); contudo, o P imobilizado pelas populações microbianas é pouco avaliado (Rheinheimer et al., 2000; Chen \& He, 2004; Martinazzo et al., 2007).

Bowman \& Cole (1978) foram os pioneiros na determinação do PBM, submetendo as amostras de solo ao tratamento com tolueno. A diferença na concentração de $\mathrm{P}$ extraído com $\mathrm{NaHCO}_{3} 0,5 \mathrm{~mol} \mathrm{~L}^{-1}$, $\mathrm{pH} 8,5$, entre as amostras tratadas e as não tratadas representou o PBM. Pressupondo que a proporção entre Pi e Po depende da concentração do elemento na solução do solo, da percentagem de $\mathrm{P}$ na célula microbiana e da idade da célula e que existem diferenças entre células fúngicas e bacterianas quanto à composição e ao conteúdo de $\mathrm{P}$, Hedley \& Stewart (1982) propuseram algumas modificações no método mencionado. Segundo esses autores, a remoção do Pi lábil com membrana de troca aniônica, anterior à adição de clorofórmio e $\mathrm{NaHCO}_{3}$, e a alteração no tempo de extração de 30 min para $16 \mathrm{~h}$ permitiram maior exatidão na quantificação do PBM.

Com o intuito de desenvolver um método alternativo, Brookes et al. (1982) enfatizaram a adsorção de $\mathrm{P}$ inorgânico à superfície dos coloides do solo, durante o período de extração, e procuraram corrigir essa perda estimando o $\mathrm{P}$ adsorvido em amostras não fumigadas. Os trabalhos posteriores adotaram esse método como padrão. Entretanto, McLaughlin et al. (1986), procurando esclarecer questionamentos sobre algumas etapas do método precedente, testaram diversos biocidas, tempos de fumigação, tempo de agitação, além do fator de correção $\mathrm{K}_{\mathrm{P}}$, que considera a proporção do $\mathrm{P}$ recuperado no processo de extração após a fumigação. Esses autores definiram que, apesar de clorofórmio e 
hexanol terem desempenho semelhante como biocidas, o último seria o mais indicado por não apresentar características carcinogênicas; $\mathrm{NaHCO}_{3} 0,5 \mathrm{~mol} \mathrm{~L}^{-1}$, $\mathrm{pH} 8,5$, foi o extrator recomendado, na relação solo:extrator de 1:20, em 30 min de agitação; eles ressaltaram a importância da determinação do fator $\mathrm{K}_{\mathrm{P}}$ para cada amostra, haja vista os solos analisados apresentarem proporções distintas entre populações e, dentro das populações, diferenças quanto às espécies predominantes. Recentemente, Bliss et al. (2004) sugeriram uma solução de oxalato $0,003 \mathrm{~mol} \mathrm{~L}^{-1}$ como extrator do $\mathrm{PBM}$ e concluíram que o fator $\mathrm{K}_{\mathrm{P}}$ deveria ser determinado para cada solo.

$\mathrm{O}$ ponto-chave dos métodos mencionados, mais conhecidos por métodos da fumigação-extração (FE), é a utilização do clorofórmio como biocida. Entretanto, muitas restrições são feitas ao seu uso, em decorrência dos cuidados que exige por ser um produto tóxico. Esse fato estimulou a busca de alternativas às técnicas existentes. A eficiência da irradiação com micro-ondas como biocida, comprovada em alguns estudos (Vela \& Wu, 1979; Ferris, 1984), serviu de suporte ao trabalho desenvolvido por Speir et al. (1986), no qual se avaliou o tempo de exposição das amostras de solo à irradiação com micro-ondas em substituição à fumigação com clorofórmio. Segundo esses autores, a irradiação com micro-ondas em $25 \mathrm{~g}$ de solo, durante $90 \mathrm{~s}$, foi efetiva como biocida, equivalendo ao obtido com clorofórmio. Contudo, o P extraível foi subestimado, provavelmente por inativação das fosfatases intracelulares, em resposta ao aquecimento provocado pela irradiação.

$\mathrm{O}$ extrato obtido da agitação do solo com $\mathrm{NaHCO}_{3}$ apresenta, geralmente, coloração escura devido à solubilização de substâncias húmicas durante a extração, interferindo na determinação colorimétrica do P. Kouno et al. (1995), procurando contornar esse aspecto negativo do método proposto por Bowman \& Cole (1978), desenvolveram um método no qual uma membrana de troca aniônica foi empregada como extrator do PBM. Estes autores encontraram correlação positiva altamente significativa do PBM pelos dois métodos, sugerindo o emprego do novo método em substituição ao tradicional. Além disso, a adsorção ao solo do P liberado dos microrganismos, durante os períodos de fumigação e extração pelo método $\mathrm{FE}$, seria minimizada com o uso da membrana.

Brookes et al. (1982) não consideraram as reações de adsorção que ocorriam durante o período de fumigação por acreditarem que a maior parte do PBM liberado, após a ruptura celular, permanecia no interior ou próxima da célula, não interagindo com o solo. Essa questão foi estudada por Morel et al. (1996), que avaliaram as reações de adsorção do $\mathrm{P}$ adotando 0 seguinte procedimento: soluções contendo doses crescentes de $\mathrm{P}\left(0,2,5,10,20\right.$ e $50 \mathrm{mg} \mathrm{kg}^{-1}$ de $\mathrm{P}$ adicionado na forma de $\mathrm{KH}_{2} \mathrm{PO}_{4}$, denominado $\mathrm{P}$ adicionado - $\mathrm{Pad}$ ) foram adicionadas a amostras de solo fumigadas e não fumigadas por 135 min e, após $40 \mathrm{~h}$, foi medida a concentração de $\mathrm{P}$ em cada amostra (P na solução - Ps), ajustando-se uma equação com os valores de Ps e Pad. Os valores encontrados de PBM pelo método convencional representaram cerca de 22 a $50 \%$ daqueles obtidos com a nova proposta, o que validou a hipótese de que a quantificação da fração adsorvida durante a fumigação permite que se tenha maior exatidão na determinação do PBM. Contudo, os solos testados apresentavam baixa a média capacidade de adsorção de $\mathrm{P}$, permanecendo a incógnita com relação a solos com elevada capacidade de adsorção. Essa dúvida fez com que Oberson et al. (1997) testassem esse método em solos tropicais altamente intemperizados da Colômbia (Oxisols e Ultisols), com média a elevada capacidade de adsorção de P. Apesar de não conseguirem detectar variações do Ps nesses solos, esses autores fizeram ajustes que viabilizaram a aplicação do método proposto neles. Entre as adaptações apresentadas, a substituição do extrator $\mathrm{NaHCO}_{3} 0,5 \mathrm{~mol} \mathrm{~L}^{-1}, \mathrm{pH} 8,5$, por $\mathrm{NH}_{4} \mathrm{~F}$ $0,03 \mathrm{~mol} \mathrm{~L}^{-1}+\mathrm{HCl} 0,025 \mathrm{~mol} \mathrm{~L}^{-1}$ tem sido bastante utilizada (He et al., 1997; Gijsman et al., 1997; Wu et al., 2000).

Considerando a importância da biomassa microbiana do solo (BMS) na ciclagem de nutrientes e como indicador de qualidade do solo, duas questões são relevantes: (1) Que método é o mais adequado à determinação do P microbiano nas condições tropicais? e (2) A cobertura florestal influencia a eficiência do método?

Diante do exposto, o presente trabalho foi realizado com o objetivo de avaliar a eficiência de três métodos de determinação do fósforo microbiano (fumigaçãoextração, irradiação com micro-ondas-extração e irradiação com micro-ondas-extração com membrana de troca aniônica) em solo com diferentes coberturas vegetais.

\section{MATERIAL E MÉTODOS}

Amostras de solo foram coletadas em áreas cultivadas com Pinus taeda, Eucalyptus grandis e floresta nativa, com aproximadamente 20 anos de idade, em um Latossolo Vermelho-Amarelo distrófico muito argiloso - LVAd, no município de Viçosa (MG).

Sob cada cobertura, estabeleceu-se uma parcela de $600 \mathrm{~m}^{2}$, de onde se obteve uma amostra composta de solo a partir de 10 subamostras simples, nas profundidades de $0-5$ e $5-10 \mathrm{~cm}$. O experimento constituiu-se de um fatorial $3 \times 3$, correspondendo, respectivamente, às três coberturas de solo (pínus, eucalipto e floresta nativa) e aos três métodos de determinação de PBM (FE, IE e EMTA). O delineamento experimental foi o inteiramente casualizado, com três repetições. Essas amostras foram homogeneizadas, secas ao ar e peneiradas em malha de $2 \mathrm{~mm}$. Em seguida, foram encaminhadas às caracterizações física e químicas, que consistiram na análise granulométrica (Embrapa, 1979) e determinação de: $\mathrm{pH}$ em água; $\mathrm{Ca}, \mathrm{Mg}$ e $\mathrm{Al}$ trocáveis, 
extraídos com $\mathrm{KCl} 1 \mathrm{~mol} \mathrm{~L}^{-1}$; $\mathrm{K}$ e P, pelo extrator Mehlich-1; N total, pelo método Kjeldahl (Embrapa, 1997); e C orgânico, conforme Tedesco et al. (1995) (Quadro 1).

Outra amostra composta foi coletada para avaliação da biomassa microbiana. Essas amostras foram destorroadas, peneiradas em malha de $2 \mathrm{~mm}$ e homogeneizadas. Os resíduos vegetais foram retirados, e o solo, acondicionado em potes plásticos e armazenado sob refrigeração (aproximadamente $4{ }^{\circ} \mathrm{C}$ ), até o momento das análises. A umidade dessas amostras foi ajustada para $60 \%$ da capacidade de retenção de água. As amostras de solo foram retiradas do refrigerador pelo menos uma hora antes das pesagens.

\section{Fósforo da biomassa microbiana do solo (PBM)}

Para estimar o PBM, foram avaliados três métodos:

\section{Método fumigação - extração (FE)}

Consiste na adaptação dos métodos propostos por Brookes et al. (1982) e Hedley \& Stewart (1982). Seis porções equivalentes a $1,5 \mathrm{~g}$ de solo seco foram pesadas em frasco de $50 \mathrm{~mL}$ (três destinadas à fumigação e três não fumigadas). As amostras destinadas à fumigação foram colocadas em dessecador contendo um frasco com $30 \mathrm{~mL}$ de clorofórmio (isento de álcool), em ambiente escurecido e com temperatura ambiente. O clorofórmio foi removido por aspirações sucessivas, após $24 \mathrm{~h}$, e o PBM, extraído com $30 \mathrm{~mL}$ de $\mathrm{NaHCO}_{3}$ $0,5 \mathrm{~mol} \mathrm{~L}^{-1}, \mathrm{pH} 8,5$. Após agitação por uma hora, a $150 \mathrm{rpm}$, os extratos foram centrifugados a $5.000 \mathrm{rpm}$, por 10 min, e filtrados em papel de filtragem lenta. Do extrato filtrado, efetuou-se a transferência de $20 \mathrm{~mL}$ para um frasco $(150 \mathrm{~mL})$, com posterior adição de 2,0 $\mathrm{mL}$ de $\mathrm{HCl} 10 \mathrm{~mol} \mathrm{~L}^{-1}$. A mistura foi agitada lentamente (ocorre liberação de $\mathrm{CO}_{2}$ ), manualmente, e, após $30 \mathrm{~min}$, foi novamente filtrada para descarte do resíduo formado (essa etapa tem por finalidade promover a clarificação da solução pela precipitação de ácidos húmicos solubilizados durante o processo de extração). Paralelamente ao processo de FE das amostras de solo, estimou-se a fração de P liberada com a fumigação e adsorvida durante a extração. Três porções de $1,5 \mathrm{~g}$ de solo seco foram pesadas em frascos de $50 \mathrm{~mL}$ e a elas adicionado $1,0 \mathrm{~mL}$ de solução contendo $25 \mathrm{mg} \mathrm{L}^{-1}$ de $\mathrm{P}$ e $30 \mathrm{~mL}$ da solução de $\mathrm{NaHCO}_{3} \quad 0,5 \mathrm{~mol} \mathrm{~L}^{-1}, \mathrm{pH} 8,5$. Após agitação por $60 \mathrm{~min}$, as amostras foram centrifugadas $(5.000 \mathrm{rpm}$, $10 \mathrm{~min}$ ) e filtradas (papel de filtragem lenta). Nas três etapas, determinou-se o $\mathrm{P}$ por espectrofotometria a $882 \mathrm{~nm}$, de acordo com Murphy \& Riley (1962).

\section{Método irradiação com micro-ondas - extração (IE)}

Este método difere do método $\mathrm{FE}$ apenas no que diz respeito à etapa de irradiação das amostras de solo (Islam \& Weil, 1998). A irradiação consiste em expor as amostras de solo a uma determinada quantidade de energia (em $\mathrm{J} \mathrm{g}^{-1}$ de solo). Foi utilizado forno de micro-ondas para uso doméstico, modelo UM $31 \mathrm{~A}$, com tensão de alimentação de $120 \mathrm{~V}(60 \mathrm{~Hz})$, frequência de alimentação de $2.450 \mathrm{MHz}$ e concentração de energia de 1,35 KW. Determinou-se a quantidade de energia emitida na cavidade interna do forno de microondas e o tempo necessário para irradiação de cada amostra de solo. Porções equivalentes a 1,5 g de solo seco foram colocadas em frascos de $100 \mathrm{~mL}$, sendo três submetidas à irradiação e três não. A umidade das amostras foi controlada, pesando-as antes e depois da irradiação, e corrigida quando necessário. Aguardouse o esfriamento das amostras à temperatura ambiente. A solução extratora foi, então, adicionada, efetuando-se todas as etapas do processo de extração do PBM de modo semelhante ao método FE.

\section{Método extração com membrana de troca aniônica (EMTA)}

As análises foram executadas conforme Kouno et al. (1995). O método consiste na agitação de $1,5 \mathrm{~g}$ de solo seco, em água deionizada, adicionando-se ou não clorofórmio (amostras fumigadas e não fumigadas, em

Quadro 1. Teor de argila e características químicas de um Latossolo Vermelho-Amarelo distrófico sob Pinus taeda, Eucalyptus grandis e floresta nativa, coletado em duas profundidades

$\begin{array}{lllllllllllllll}\text { Cobertura vegetal } & \text { Profundidade Argila } & \mathrm{pH}_{\mathrm{H}_{2} \mathrm{O}} & \mathrm{CO} & \mathrm{N} & \mathrm{P} & \mathrm{K} & \mathrm{Ca} & \mathrm{Mg} & \mathrm{Al} & \mathrm{SB} & \mathrm{CTC} \text { efet. } & \mathrm{m}\end{array}$

\begin{tabular}{|c|c|c|c|c|c|c|c|c|c|c|c|c|c|}
\hline \multirow[b]{2}{*}{ Pinus taeda } & \multirow{2}{*}{$\begin{array}{c}\mathrm{cm} \\
0-5\end{array}$} & \multicolumn{2}{|l|}{$\mathrm{g} \mathrm{kg}^{-1}$} & \multicolumn{2}{|c|}{$-\mathrm{g} \mathrm{kg}^{-1} \_$} & \multicolumn{2}{|c|}{$-\mathrm{mg} \mathrm{dm}^{-3}$} & \multicolumn{5}{|c|}{$\longrightarrow \mathrm{cmol}_{\mathrm{c}} \mathrm{dm}^{-3}$} & \multirow{2}{*}{$\begin{array}{r}\% \\
75\end{array}$} \\
\hline & & 740 & 4,36 & 35,9 & 1,70 & 4,8 & 32,4 & 0,19 & 0,54 & 2,4 & 0,81 & 3,21 & \\
\hline & $5-10$ & 740 & 4,22 & 26,0 & 1,35 & 2,8 & 23,0 & 0,00 & 0,35 & 2,8 & 0,41 & 3,21 & 87 \\
\hline \multirow[t]{2}{*}{ Eucalyptus grandis } & $0-5$ & 730 & 3,47 & 39,5 & 1,74 & 3,8 & 39,8 & 0,08 & 0,76 & 2,4 & 0,94 & 3,34 & 72 \\
\hline & $5-10$ & 730 & 3,32 & 30,4 & 1,45 & 2,9 & 30,9 & 0,00 & 0,52 & 3,0 & 0,60 & 3,60 & 83 \\
\hline \multirow{2}{*}{ Floresta nativa } & $0-5$ & 740 & 4,41 & 36,9 & 2,34 & 3,6 & 51,2 & 6,04 & 2,91 & 0,8 & 9,09 & 9,89 & 8 \\
\hline & $5-10$ & 740 & 3,81 & 22,2 & 1,49 & 2,2 & 33,9 & 1,49 & 1,61 & 1,1 & 3,18 & 4,28 & 26 \\
\hline
\end{tabular}


triplicata), e adição de uma lâmina de membrana de troca aniônica - MTA (tipo 204 UZRA 435, produzida por Ionics Incorporated, Watertown, MA, USA). As lâminas de MTA, de $10 \mathrm{~cm}^{2}(2,0 \times 5,0 \mathrm{~cm})$, foram saturadas com cloreto, utilizando $\mathrm{NaCl} 1 \mathrm{~mol} \mathrm{~L}^{-1}$. Tanto o pré-condicionamento como a extração do $\mathrm{P}$ da membrana foram realizados conforme Cooperband \& Logan (1994). Após $16 \mathrm{~h}$ de agitação a 150 rpm, as lâminas foram retiradas com o auxílio de uma pinça, lavadas com jatos de água deionizada para remoção da argila aderida, imersas em $30 \mathrm{~mL}$ de solução de $\mathrm{HCl} 0,5 \mathrm{~mol} \mathrm{~L}^{-1}$ e agitadas, por $60 \mathrm{~min}$, a $150 \mathrm{rpm}$. $\mathrm{O}$ mesmo procedimento foi adotado na avaliação da fração adsorvida. Neste método, não houve necessidade de realizar a clarificação do extrato. O P no extrato foi determinado pelo método de Murphy \& Riley (1962).

\section{Cálculos para determinação do PBM}

A concentração de PBM (mg kg-1 de P no solo) nos extratos das amostras fumigadas/irradiadas $\left(\mathrm{P}_{F U M I G}\right.$ ou $\left.\mathrm{P}_{\text {IRRAD }}\right)$ e não fumigadas/não irradiadas $\left(\mathrm{P}_{\text {NFUMIG }}\right.$ ou $\mathrm{P}_{\text {NIRRAD }}$ ) foi calculada da seguinte forma:

$$
\begin{gathered}
\text { P líquido }=\left(\mathrm{P}_{\text {FUMIG }} \text { ou } \mathrm{P}_{\text {IRRAD }}\right)-\left(\mathrm{P}_{\text {NFUMIG }} \text { ou } \mathrm{P}_{\text {NIRRAD }}\right) \\
\operatorname{PBM}\left(\mathrm{mg} \mathrm{kg}^{-1} \text { de } \mathrm{P} \text { no solo }\right)=(\mathrm{P} \text { líquido } / 0,40) \mathrm{x} \\
(100 / \% \mathrm{P} \text { rec })
\end{gathered}
$$

em que 0,40 é a fração de PBM convertido em Pi pela fumigação ou irradiação (Brookes et al., 1982).

\section{Percentagem de $P$ recuperado ( $P$ rec)}

$$
\begin{gathered}
\% \text { Prec }=\left(\text { P adicionado }-\mathrm{P}_{\text {NFUMIG }} \text { ou } \mathrm{P}_{\text {NIRRAD }}\right) / 16,67 \\
\mathrm{x} 100
\end{gathered}
$$

em que $\mathrm{P}$ adicionado corresponde a $1,0 \mathrm{~mL}$ de solução contendo $25 \mathrm{mg} \mathrm{L}^{-1}$ de $\mathrm{P}$, equivalendo a $16,67 \mathrm{mg} \mathrm{kg}^{-1}$ de $\mathrm{P}$ no solo.

\section{Análises estatísticas}

Os dados foram submetidos à análise de variância, utilizando o programa SAEG (Sistema para Análises Estatísticas, versão 8.0/1999). As médias de cada método de extração do PBM, em cada profundidade, dentro de cada cobertura vegetal, foram comparadas pelo teste de Tukey a $5 \%$.

\section{RESULTADOS E DISCUSSÃO}

Em termos gerais, entre os três métodos avaliados, menores teores de PBM foram obtidos com o método irradiação-extração (IE), sendo eles similares entre os outros dois métodos (Quadro 2). Os teores de PBM obtidos com o método IE corresponderam a $33 \%$ daqueles obtidos pelo método fumigação-extração (FE), considerado método-padrão, nas áreas com floresta de eucalipto e floresta nativa, especialmente na camada superficial. Os teores de PBM encontrados sob floresta nativa diferiram significativamente $(\mathrm{p}<0,05)$ daqueles sob floresta de eucalipto, nas duas profundidades, e foram semelhantes ao PBM sob pínus.

Hendricks \& Pascoe (1988) encontraram resultados bastante contraditórios quando compararam o teor de $\mathrm{P}$ inorgânico (Pi) em amostras de solo com e sem irradiação e clorofórmio, pois somente no solo com maior fertilidade foi possível detectar alterações no teor de Pi em resposta à irradiação. Segundo esses autores, há uma série de fatores que interferem na determinação da BMS, e eles chamam a atenção para a diversidade em número e tipos de organismos que compõem esse compartimento, os quais apresentam sensibilidade diferenciada aos tratamentos aplicados.

Questão semelhante foi abordada por Speir et al. (1986) ao testarem a eficiência da irradiação com micro-ondas em populações de eucariotas e procariotas. As populações foram igualmente sensíveis ao novo biocida. Todavia, as bactérias mostraram-se menos sensíveis à irradiação, sendo necessário maior tempo de exposição à irradiação para se obter maior eficiência do método. A taxa respiratória de fungos decresceu significativamente após exposição a $6.000 \mathrm{~J} \mathrm{~g}^{-1}$ de solo, e a de bactérias, a $12.000 \mathrm{~J} \mathrm{~g}^{-1}$.

No presente trabalho, as amostras foram expostas a $800 \mathrm{~J} \mathrm{~g}^{-1}$ de solo (correspondendo a $2,110^{5} \mathrm{~J}$ ), quantidade de irradiação testada por Islam \& Weil (1998) e considerada adequada para se obter rápida redução da atividade microbiana e máxima liberação de $\mathrm{C}$ microbiano. Considerando-se os valores de irradiação mencionados nos trabalhos supracitados, provavelmente os $800 \mathrm{~J} \mathrm{~g}^{-1}$ de solo aqui empregados não foram suficientes para provocar o rompimento completo da parede celular da população microbiana, impedindo que o extrator retirasse o Pi intracelular, o que explicaria os baixos teores de PBM detectados. Dois outros aspectos podem ser considerados: a irradiação poderia estar liberando $\mathrm{P}$ de fontes distintas daquelas liberadas com a fumigação; e, dependendo da concentração de $\mathrm{Pi}$, e mesmo de $\mathrm{Po}$, na solução extratora, o Pi estimado poderia ser tanto sub como superestimado. Essas afirmativas baseiam-se nos resultados obtidos por Puri \& Barraclough (1993) e Dick \& Tabatabai (1977). Os primeiros autores determinaram o $\mathrm{N}$ da biomassa microbiana (NBM), pelos métodos da FE e IE, expondo amostras de solos tratadas com ${ }^{15} \mathrm{~N}$ à irradiação correspondente a $731 \mathrm{e}$ $3.188 \mathrm{~J} \mathrm{~g}^{-1}$ de solo. Estes autores verificaram que os teores de NBM obtidos pelos métodos não se originavam das mesmas fontes orgânicas de $\mathrm{N}$ e que a irradiação mais intensa estaria liberando formas mais lábeis de compostos orgânicos ligados à matéria orgânica do solo e não exclusivamente da população microbiana. Dick \& Tabatabai (1977), ao proporem um novo método colorimétrico para determinação de $\mathrm{P}$, verificaram que a recuperação de $\mathrm{P}$, na forma de 
ortofosfato, foi extremamente influenciada pela concentração de compostos orgânicos e inorgânicos de P na solução. Conforme esses autores, essa diferença pode ser atribuída à hidrólise das formas mais lábeis de $\mathrm{P}$ em ambos os compostos, que, por sua vez, é influenciada pela concentração de ortofosfatos, acidez e temperatura do meio. Segundo Tabatabai (1994), a hidrólise de polifosfatos pode ocorrer em consequência de uma série de reações bioquímicas, catalisadas por enzimas, ou quimicamente, por soluções ácidas ou básicas, especialmente na presença de certos cátions $\left(\mathrm{Ca}^{2+} \mathrm{e} \mathrm{Mg}^{2+}\right)$.

Com relação ao método $\mathrm{FE}$, a diferença no $\mathrm{PBM}$ determinado nas três coberturas foi significativa ( $\mathrm{p}<0,05$ ), com valores variando de 2,68 a $8,0 \mathrm{mg} \mathrm{kg}^{-1}$, na camada de $0-5 \mathrm{~cm}$, e, na de $5-10 \mathrm{~cm}$, somente o PBM sob pínus foi significativamente menor (2,66 $\mathrm{mg} \mathrm{kg}^{-1}$ ) (Quadro 2). Já com o método EMTA, o PBM extraído foi semelhante sob floresta de eucalipto e de pínus (2,05 a 3,16 $\left.\mathrm{mg} \mathrm{kg}^{-1}\right)$ nas duas profundidades, porém os teores encontrados sob floresta nativa foram significativamente superiores: $8,93 \mathrm{e}$ $7,84 \mathrm{mg} \mathrm{kg}^{-1}$, respectivamente nas camadas de $0-5$ e 5-10 cm. Esse resultado assemelha-se ao encontrado por Myers et al. (1999), que detectaram grande variação entre os teores de PBM determinados pelos métodos FE e EMTA. O uso da membrana de troca aniônica (MTA) na avaliação do PBM foi recomendado por Kouno et al. (1995) para minimizar o efeito da adsorção de P. Estes autores alegaram que a MTA mantém, durante o período de extração, o $\mathrm{P}$ em solução em baixas concentrações, favorecendo, assim, a liberação do $\mathrm{P}$ das células microbianas para a solução e, com isso, inibindo a adsorção do elemento ao solo. Essa argumen- tação pode ser observada no presente trabalho, quando os valores de PBM obtidos pelos métodos IE e EMTA são comparados. Sob floresta de eucalipto, o PBM extraído pelo método IE correspondeu a $55 \%$ do obtido pelo método EMTA, e sob floresta nativa, a $29 \%$, na camada superficial.

Nos trabalhos que comparam métodos de determinação de PBM, nenhuma inferência foi feita com relação à influência do tipo de vegetação encontrado na área amostrada (Hendricks \& Pascoe, 1988; Kouno et al., 1995). A variação nos valores encontrados reflete, provavelmente, a composição da biomassa microbiana do solo e a qualidade da matéria orgânica nas áreas estudadas - premissa que justificaria as diferenças, dentro de cada método, entre coberturas (Quadro 2). Apesar do reduzido número de trabalhos que quantificam o PBM em ecossistemas florestais e, mais especificamente, em condições tropicais, os valores encontrados são bastante inferiores aos de Sparling et al. (1994), que foram de 52,3 e $32,4 \mathrm{mg} \mathrm{kg}^{-1}$ de P no solo, respectivamente, na biomassa microbiana em áreas de floresta nativa e plantações de Pinus radiata, na Nova Zelândia. Na área com eucalipto, os valores de PBM apresentaram tendência semelhante à dos resultados apresentados por Polglase et al. (1992) ao quantificarem o PBM em plantações de Eucalyptus regnans, na Austrália, com várias idades, os quais verificaram aumento do PBM com a idade do povoamento. O PBM variou de $1,8 \mathrm{mg} \mathrm{kg}^{-1}$ de $\mathrm{P}$ no solo, na época do plantio, a $98,7 \mathrm{mg} \mathrm{kg}^{-1}$ de $\mathrm{P}$ no solo, aos 80 anos. Nos povoamentos com cinco anos, o PBM era de $28,7 \mathrm{mg} \mathrm{kg}^{-1}$ de P no solo - cerca de cinco vezes superior ao encontrado neste trabalho, cujos povoamentos estavam com 20 anos de idade.

Quadro 2. Fósforo da biomassa microbiana (PBM) avaliado pelos métodos fumigação-extração, irradiaçãoextração e irradiação-extração com membrana de troca aniônica (EMTA), em solo com Pinus taeda, Eucalyptus grandis e floresta nativa, em duas profundidades

\begin{tabular}{|c|c|c|c|c|c|c|c|c|}
\hline \multirow{3}{*}{ Cobertura vegetal } & \multicolumn{8}{|c|}{ Método } \\
\hline & \multicolumn{2}{|c|}{ Fumigação-extração } & \multicolumn{2}{|c|}{ Irradiação-extração } & \multicolumn{2}{|c|}{ Irradiação-EMTA } & \multicolumn{2}{|c|}{ Média da cobertura } \\
\hline & $0-5 \mathrm{~cm}$ & $5-10 \mathrm{~cm}$ & $0-5 \mathrm{~cm}$ & $5-10 \mathrm{~cm}$ & $0-5 \mathrm{~cm}$ & $5-10 \mathrm{~cm}$ & $0-5 \mathrm{~cm}$ & $5-10 \mathrm{~cm}$ \\
\hline & & & & $\mathrm{mg} \mathrm{kg}^{-1}$ & & & & \\
\hline Pinus taeda & $2,68 \pm 0,28 \mathrm{cA}$ & $2,66 \pm 0,34 \mathrm{bB}$ & $2,24 \pm 0,04 \mathrm{abB}$ & $3,47 \pm 0,35 \mathrm{aA}$ & $2,97 \pm 0,15 \mathrm{bA}$ & $2,56 \pm 0,25 \mathrm{bB}$ & 2,63 & 2,90 \\
\hline CV (\%) & 10,5 & 12,7 & 2,0 & 7,0 & 5,2 & 10,0 & & \\
\hline Eucalyptus grandis & $5,26 \pm 0,11 \mathrm{bA}$ & $4,04 \pm 0,28 \mathrm{aA}$ & $1,74 \pm 0,20 \mathrm{bC}$ & $1,90 \pm 0,04 \mathrm{bB}$ & $3,16 \pm 0,04 \mathrm{bB}$ & $2,05 \pm 0,26 \mathrm{bB}$ & 3,65 & 2,66 \\
\hline CV (\%) & 2,0 & 7,0 & 11,6 & 2,0 & 1,3 & 11,9 & & \\
\hline Floresta nativa & $8,00 \pm 0,43 \mathrm{aB}$ & $4,58 \pm 0,15 \mathrm{aB}$ & $2,61 \pm 0,27 \mathrm{aC}$ & $3,03 \pm 0,09 a \mathrm{C}$ & $8,93 \pm 0,75 \mathrm{aA}$ & $7,84 \pm 0,37 \mathrm{aA}$ & 6,51 & 5,15 \\
\hline CV (\%) & 5,4 & 3,3 & 10,4 & 3,1 & 8,4 & 8,8 & & \\
\hline Média do método & $5,43 \pm 2,32$ & $3,76 \pm 0,89$ & $2,19 \pm 0,41$ & $2,76 \pm 0,65$ & $5,02 \pm 2,96$ & $4,20 \pm 2,75$ & & \\
\hline CV (\%) & 5,6 & 7,2 & 9,0 & 7,5 & 8,8 & 7,1 & & \\
\hline
\end{tabular}

土 desvio-padrão da média; CV: coeficiente de variação. Médias seguidas pela mesma letra minúscula, na coluna, e maiúscula, na linha, em cada profundidade, não diferem entre si pelo teste de Tukey a $5 \%$. 
Os valores dos coeficientes de variação (CV) dos teores de PBM foram bastante distintos entre coberturas do solo (1,3 a $12,7 \%)$. Entre métodos, apenas o CV obtido com o método FE foi inferior aos demais, na camada superficial, retratando maior precisão do método (Quadro 2). Na camada subsuperficial, esses valores foram semelhantes. O resultado encontrado contradiz aquele apresentado por Ferreira et al. (1999), ao compararem os métodos FE e IE. Esses autores encontraram menores valores de CV nas amostras irradiadas, sugerindo que o método da irradiação-extração fosse indicado como o mais adequado para estimar o $\mathrm{C}$ e o $\mathrm{N}$ da biomassa microbiana do solo. Com relação às coberturas do solo, a grande variação observada nos valores de CV inviabiliza a escolha de um único método que apresente maior precisão na avaliação do PBM. Por exemplo, na profundidade de $0-5 \mathrm{~cm}$, as sequências observadas, levando-se em consideração o CV, foram: com pínus, IE $<$ EMTA $<$ FE; com eucalipto, EMTA $<$ FE $<$ IE; e, com floresta nativa, $\mathrm{FE}<$ EMTA $<$ IE.

\section{Considerações sobre os métodos testados}

Ao avaliar os três métodos de determinação do PBM do solo, procurou-se observar as diferenças operacionais de cada um, como o tempo gasto em cada etapa, as particularidades na aplicação do biocida, na extração e, ou, na determinação do P. Entre os aspectos observados, a aplicação do biocida destacase. A etapa de fumigação é demorada, não apenas pelo período necessário à fumigação $(24 \mathrm{~h})$, mas pela limitação operacional, pois um dessecador comporta número restrito de béqueres. A agitação com MTA, por $16 \mathrm{~h}$, também torna o processo demorado. Uma vantagem do método IE é o tempo consumido na etapa de irradiação das amostras que é bastante reduzido, se comparado à fumigação (cerca de 20 s para irradiar nove amostras de solo de $1,8 \mathrm{~g}$ ). Observou-se certa dificuldade ao transferir a amostra de solo úmido, após fumigação, para o recipiente usado na etapa de extração, tornando-se necessária a lavagem do primeiro recipiente com um pouco de $\mathrm{NaHCO}_{3}$. A solubilização de substâncias húmicas, provocada pela solução de $\mathrm{NaHCO}_{3}$, escurece os extratos oriundos da FE e IE, dificultando a determinação colorimétrica do $\mathrm{P}$, fato que não ocorre no método EMTA. A acidificação do extrato com $\mathrm{HCl} 10 \mathrm{~mol} \mathrm{~L}^{-1}$ torna-se essencial, pois precipita ácidos húmicos, clarificando o extrato. Com relação ao método da EMTA, em ensaio preliminar, observou-se que os teores de $\mathrm{P}$ extraídos eram muito baixos quando se adicionava clorofórmio depois da adição de água destilada ou deionizada. Quando o clorofórmio foi adicionado diretamente sobre o solo, com posterior adição da água e da membrana, os resultados foram satisfatórios. Outro ponto negativo do método EMTA foi a etapa de lavagem das lâminas com água destilada, após agitação e precedente à extração do $\mathrm{P}$, para remoção de argila que tenha ficado aderida à membrana. Essa etapa consome, para uma bateria de 40 lâminas, em média, $90 \mathrm{~min}$, principalmente se o solo for argiloso.
Considerando as vantagens e desvantagens operacionais de cada método, as características químicas do solo com cada cobertura vegetal e os resultados obtidos neste estudo, verifica-se que o método $\mathrm{FE}$ foi o que apresentou maior precisão na determinação do PBM. Entretanto, levando-se em conta apenas os aspectos operacionais, o método IE mostrou-se mais apropriado no caso de maior número de amostras a serem analisadas, pela redução no tempo gasto na execução do método como um todo e, especialmente, na etapa de aplicação do biocida. Todavia, ressalta-se que, apesar de os três métodos serem comprovadamente eficientes na determinação do $\mathrm{C}$ e $\mathrm{N}$ microbianos, análises mais minuciosas são necessárias, proporcionando melhor ajuste nas determinações do PBM, especialmente com relação ao método IE. Além disso, a aplicabilidade dos métodos deve ser avaliada com maior cautela em solos altamente intemperizados, com elevada capacidade de retenção de $\mathrm{P}$, procurando-se minimizar os efeitos dessa característica sobre a referida fração.

\section{CONCLUSÕES}

1. Maiores teores médios de PBM foram obtidos com o método fumigação-extração, o qual se mostrou mais adequado para as condições estudadas.

2. O método irradiação-extração mostrou-se, em termos operacionais, o mais adequado à determinação do PBM quando há maior número de amostras a serem analisadas.

3. Dada a grande variabilidade nos coeficientes de variação obtidos para cada cobertura, nos três métodos testados, não foi possível definir qual deles apresenta maior precisão na avaliação do PBM.

\section{LITERATURA CITADA}

BARROTI, G. \& NAHAS, E. População microbiana total e solubilizadora de fosfato em solo submetido a diferentes sistemas de cultivo. Pesq. Agropec. Bras., 35:2043-2050, 2000 .

BOWMAN, R.A. \& COLE, C.V. Transformations of organic phosphorus substrates in soils evaluated by $\mathrm{NaHCO}_{3}$ extraction. Soil Sci., 125:49-54, 1978.

BLISS, C.M.; COMERFORD, N.B. \& MUCHOVEJ, R.M. Determination of microbial phosphorus $\mathrm{Kp}$ factors in a spodosol: Influence of extractant, water potential, and soil horizon. Soil Biol. Biochem., 36:1925-1934, 2004.

BROOKES, P.C.; POWLSON, D.S. \& JENKINSON, D.S. Measurement of microbial biomass phosphorus in soil. Soil Biol. Biochem, 14:319-329, 1982.

CHEN, G.-C. \& HE, Z.-L. Determination of soil microbial biomass phosphorus in acid red soils from southern China. Biol. Fert. Soils, 39:446-451, 2004. 
CONDRON, L.M.; GOH, K.M. \& NEWMAN, R.H. Nature and distribution of soil phosphorus as revealed by sequencial extraction method followed by ${ }^{31} \mathrm{P}$ nuclear magnetic resonance analysis. J. Soil Sci., 36:199-207, 1985.

COOPERBAND, L.M. \& LOGAN, T.J. Measuring in situ changes in labile soil phosphorus with anion-exchange membranes. Soil Sci. Soc. Am. J., 58:105-114, 1994

CROSS, A.F. \& SCHLESINGER, W.H. A literature review and evaluation of the Hedley fractionation: Applications to the biogeochemical cycle of soil phosphorus in natural ecosystems. Geoderma, 64:197-214, 1995.

DICK, W.A. \& TABATABAI, M.A. Determination of orthophosphate in aqueous solutions containing labile organic and inorganic phosphorus compounds. J. Environ. Qual., 6:82-85, 1977.

EMPRESA BRASILEIRA DE PESQUISA AGROPECUÁRIA EMBRAPA. Centro Nacional de Pesquisa de Solos. Manual de métodos de análise de solo. Rio de Janeiro, 1979. $212 \mathrm{p}$

EMPRESA BRASILEIRA DE PESQUISA AGROPECUÁRIA EMBRAPA. Centro Nacional de Pesquisa de Solos. Manual de métodos de análise de solo. Rio de Janeiro, 1997. 212p. (Embrapa-CNPS. Documentos, 1)

FERREIRA, A.S.; CAMARGO, F.A.O. \& VIDOR, C. Utilização de micro-ondas na avaliação da biomassa microbiana do solo. R. Bras. Ci. Solo, 23:991-996, 1999.

FERRIS, R.S. Effects of microwave oven treatment on microorganisms in soil. Phytopathology, 74:121-126, 1984.

GAMA-RODRIGUES, E.F.; BARROS, N.F.; GAMARODRIGUES, A.C. \& SANTOS, G.A. Nitrogênio, carbono e atividade da biomassa microbiana do solo em plantações de eucalipto. R. Bras. Ci. Solo, 29:893-901, 2005.

GIJSMAN, A.J.; OBERSON, A.; FRIESEN, D.K.; SANZ, J.I. \& THOMAS, R.J. Nutrient cycling through microbial biomass under rice-pasture rotations replacing native savanna. Soil Biol. Biochem., 29:1433-1441, 1997.

GIL-SOTRES, F.; ZECH, W. \& ALT, H.G. Characterization of phosphorus fractions in surface horizons of soils from Galicia (N.W. Spain) by ${ }^{31} \mathrm{P}$ NMR spectroscopy. Soil Biol. Biochem., 22:75-79, 1990.

HE, Z.L.; WU, J.; O'DONNELL, A.G. \& SYERS, J.K. Seasonal responses in microbial biomass carbon, phosphorus and sulphur in soils under pasture. Biol. Fert. Soils, 24:421428, 1997.

HEDLEY, M.J. \& STEWART, J.W.B. Method to measure microbial phosphate in soils. Soil Biol. Biochem., 14:377. 385, 1982.

HEDLEY, M.J.; STEWART, J.W.B. \& CHAUHAN, B.S. Changes in inorganic and organic soil phosphorus fraction induced by cultivation practices and by laboratory incubations. Soil Sci. Soc. Am. J., 46:970-976, 1982.

HENDRICKS, C.W. \& PASCOE, N. Soil microbial biomass estimates using $2450 \mathrm{MHz}$ microwave irradiation. Plant Soil, 110:39-47, 1988.
ISLAM, K.R. \& WEIL, R.R. Microwave irradiation of soil for routine measurement of microbial biomass carbon. Biol. Fert. Soils, 27:408-416, 1998.

KOUNO, K.; TUCHIYA, Y. \& ANDO, T. Measurement of soil microbial biomass phosphorus by an anion exchange membrane method. Soil Biol. Biochem., 27:1353-1357, 1995.

MARTINAZZO, R.; SANTOS, D.R.; GATIBONI, L.C.; BRUNETTO, G. \& KAMINSKI, J. Fósforo microbiano do solo sob sistema plantio direto em resposta à adição de fosfato solúvel. R. Bras. Ci. Solo, 31:563-570, 2007.

McLAUGHLin, M.J.; ALSTON, A.M. \& MARTIN, J.K. Measurement of phosphorus in the soil microbial biomass: A modified procedure for field soils. Soil Biol. Biochem., 18:437-443, 1986.

MOREIRA, F.M.S. \& SIQUEIRA, J.O. Microbiologia e bioquímica do solo. Lavras, Universidade Federal de Lavras, 2002. 626p.

MOREL, C.; TIESSEN, H. \& STEWART, J.W.B. Correction for P-sorption in the measurement of soil microbial biomass $\mathrm{P}$ by $\mathrm{CHCl}_{3}$ fumigation. Soil Biol. Biochem., 28:1699-1706, 1996.

MURPHY, J. \& RILEY, J.P. A modified single solution method for the determination of phosphate in natural waters. Anal. Chim. Acta, 27:31-36, 1962.

MYERS, R.G.; THIEN, S.J. \& PIERZYNSKI, G.M. Using an ion sink to extract microbial phosphorus from soil. Soil Sci. Soc. Am. J., 63:1229-1237, 1999.

OBERSON, A.; FRIESEN, D.K.; MOREL, C. \& TIESSEN, H. Determination of phosphorus released by chloroform fumigation from microbial biomass in high $\mathrm{P}$ sorbing tropical soils. Soil Biol. Biochem., 29:1579-1583, 1997.

OLIVEIRA, J.R.A.; MENDES, I.C. \& VIVALDI, L. Carbono da biomassa microbiana em solos de cerrado sob vegetação nativa e sob cultivo: Avaliação dos métodos fumigaçãoincubação e fumigação-extração. R. Bras. Ci. Solo, 25:863$871,2001$.

POLGLASE, P.J.; ATTIWILL, P.M. \& ADAMS, M.A. Nitrogen and phosphorus cycling in relation to stand age of Eucalyptus regnans F. Muell. III. Labile inorganic and organic $\mathrm{P}$, phosphatase activity and $\mathrm{P}$ availability. Plant Soil, 142:177-185, 1992.

PURI, G. \& BARRACLOUGH, D. Comparison of $2450 \mathrm{MHz}$ microwave radiation and chloroform fumigationextraction to estimate soil microbial biomass nitrogen using ${ }^{15} \mathrm{~N}$-labelling. Soil Biol. Biochem., 25:521-522, 1993.

RHEINHEIMER, D.S.; ANGHINONI, I. \& CONTE, E. Fósforo da biomassa microbiana em solos sob diferentes sistemas de manejo. R. Bras. Ci. Solo, 24:589-597, 2000.

SCHNEIDER, K.; TURRION, M-B.; GRIERSON, P.F. \& GALLARDO, J.F. Phosphatase activity, microbial phosphorus, and fine root growth in forest soils in the Sierra de Gata, western central Spain. Biol. Fert. Soils, 34:151-155, 2001.

SISTEMA PARA ANÁLISES ESTATÍSTICAS - SAEG (software). Viçosa, MG, Universidade Federal de Viçosa, 1999. 
SPARLING, G.P.; HART, P.B.S.; AUGUST, J.A. \& LESLIE, D.M. A comparison of soil and microbial carbon, nitrogen, and phosphorus contents, and macro-aggregate stability of a soil under native forest and after clearance for pastures and plantation forest. Biol. Fert. Soils, 17:91$100,1994$.

SPEIR, T.W.; COWLING, J.C.; SPARLING, AG.P.; WEST, A.W \& CORDEROY, D.M. Effects of microwave radiation on the microbial biomass, phosphatase activity and levels of extractable $\mathrm{N}$ and $\mathrm{P}$ in a low fertility soil under pasture. Soil Biol. Biochem., 18:377-382, 1986.

TABATABAI, M.A. Enzymes. In: WEAVER, R.W.; AUGLE, S.; BOTTOMLY, P.J.; BEZDICEK, D.; SMITH, S.; TABATABAI, A. \& WOLLUM, A., eds. Methods of soil analysis. Part 2. Microbiological and biochemical properties. Madison, Soil Science Society of America, 1994. p.775-833.
TEDESCO, M.J.; BOHNEM, H.; GIANELLO, C.; BISSANI, C.A. \& VOLKWEISS, S.J. Análise de solo, plantas e outros materiais. 2.ed. Porto Alegre, Universidade Federal do Rio Grande do Sul, 1995. 174p. (Boletim Técnico, 5)

VARGAS, L.K. \& SCHOLLES, D. Biomassa microbiana e produção de $\mathrm{C}-\mathrm{CO}_{2}$ e $\mathrm{N}$ mineral de um Podzólico Vermelho-Escuro submetido a diferentes sistemas de manejo. R. Bras. Ci. Solo, 24:35-42, 2000.

VELA, G.R. \& WU, J.F. Mechanism of lethal action of 2450 $\mathrm{MHz}$ radiation on microorganisms. Appl. Environ. Microbiol, 37:550-553, 1979.

WU, J.; HE, Z.L.; WEI, W.X.; O'DONNELL, A.G. \& SYERS, J.K. Quantifying microbial biomass phosphorus in acid soils. Biol. Fert. Soils, 32:500-507, 2000. 
